\title{
Improving outcomes of radical cystectomy: A call for passive over active regionalization
}

\author{
Girish S. Kulkarni, MD
}

Department of Surgical Oncology, Princess Margaret Cancer Centre and the University Health Network, University of Toronto, Toronto, ON, Canada

Cite as: Can Urol Assoc J 2020;14(4):97-8. http://dx.doi.org/10.5489/cuaj.6505

See related article on page 91

$\mathrm{R}$ adical cystectomy $(\mathrm{RC})$ is the de facto, tried-and-tested treatment for localized muscle-invasive bladder cancer (MIBC). However, RC is a complex surgical procedure with a not insignificant morbidity and mortality rate. Over the past few decades, advances that improve MIBC care have emerged. These include delivery of perioperative chemotherapy (particularly neoadjuvant chemotherapy), increased recognition of the importance of lymphadenectomy at RC, and the need for involvement of multidisciplinary care teams in MIBC decision-making, to name a few.

However, uptake of these processes of care has been sporadic, with widespread variability. High-volume centers and surgeons tend to have the highest adoption rates of these important process measures and, as a corollary, these high-volume providers also have the best outcomes for RC. In this issue of CUAJ, Siemens and colleagues describe this phenomenon in Ontario, with high-volume RC hospitals and surgeons displaying the highest probability of providing guideline-concurrent care with higher nodal yields, higher rates of lymph node dissection, higher rates of multidisciplinary referral, and more usage of neoadjuvant chemotherapy. ${ }^{1}$ Perhaps, then, it is not surprising that these same high-volume providers also generated the best cancerspecific survival.

The superior quality of care afforded RC patients by high-volume providers is not a new finding. Innumerable series from Canada, the U.S., and Europe have consistently demonstrated improved outcomes for RC when provided in high-volume settings. ${ }^{2}$ Such data have led to regionalization efforts in other parts of the world, including the U.K. ${ }^{3}$ and the U.S. ${ }^{4}$ In the U.K., the National Institute for Health and Care Excellence (NICE) has recommended that RC be performed in centers with a minimum annual volume of 50 radical pelvic cancer operations per year. ${ }^{5}$ Recent National Cancer Database analyses from the U.S. have supported this value, with incremental gains in quality of care plateauing after a 50-55 annual cystectomy caseload. ${ }^{6}$ A more recent report from the U.K. did not find any further evidence of volume outcome associations among high-volume centers after centralization, supporting this minimum caseload value and the concept of a plateau effect for morbidity and mortality. ${ }^{7}$ After centralization in the U.K.'s National Health Service (NHS), based on the NICE "improving outcomes guidance," almost $90 \%$ of cystectomies are now performed by high-volume providers, and 30-day and long-term mortality rates have dropped significantly, pointing to the potential effectiveness of centralization. ${ }^{3}$

Further substantiating evidence that complex surgical care should be concentrated, Sahni and colleagues identified a $41 \%$ relative risk reduction for cystectomy postoperative mortality in the hands of subspecialized surgeons focusing at least $23 \%$ of their case volumes on RC. ${ }^{8}$ Interestingly, in this study, $100 \%$ of the volume-outcome relationship for cystectomy was accounted for by surgeon subspecialization. These finding corroborate those of Bhindi et al, who previously demonstrated improved oncological outcomes after cystectomy in bladder cancer-focused surgeons' hands. ${ }^{9}$

With these data in mind, the Canadian Urological Association (CUA), Bladder Cancer Canada (BCC), and the Canadian Urologic Oncology Group (CUOG), in a joint statement, proposed defining bladder cancer "Centers of Expertise," as those performing at least 25 cystectomies per year. ${ }^{10}$ This volume threshold is more modest than the NICE/U.S. values but does provide balance between access to care (travel distance and wait times) and centralization of care. Nevertheless, despite dozens of studies pointing to a volume-outcome relationship for complex cancer surgery with endorsement by top Canadian bladder cancer experts, health authorities in Canada have been reluctant to implement a policy of "active" centralization for RC, even with widespread consensus that such a maneuver could improve patient outcomes. Reasons for this resistance are multifactorial, including concerns about preserving access to care for all patients given the vast geography of our nation, the risk of alienating lower-volume healthcare providers, resource 
implications for high-volume centers, and the possibility of increased wait times in a regionalized environment.

Even without formal guidance, though, there is some hope, as Darwinian forces are leading to passive centralization. Siemens and colleagues point out that in the most recent era they analyzed, $40 \%$ of RCs in Ontario are being performed at high-volume centers. ${ }^{1}$ Mean annual surgeon and hospital volumes increased to 6.8 and $16.4 \mathrm{RC}$, respectively, with documented improvements in outcome. While the reasons for this shift are not clear, we can speculate that: 1) an understanding of evolving volume effects for RC exists among the urological community; 2) there is a recognition that a multidisciplinary approach is necessary for bladder cancer care; 3 ) the relative rarity of RC eases regionalized referrals; 4) low-volume providers have an appreciation of the complexity of RC care; and 5) the emergence of patientdriven referral patterns are all likely at play.

Although this passive change represents a move in the right direction, a volume-outcome effect is still noted in Ontario, pointing to the need for continued change. The fact that $60 \%$ of RCs are still being performed by lower-volume providers is disturbing. In other words, more than half of current RC patients are receiving care that yields suboptimal survival. Bladder cancer requiring RC already has a high overall cancer-specific mortality rate. If governmental agencies are not willing to centralize care, we should, as a urological community, strive to optimize treatment outcomes for our bladder cancer patients with a passive campaign of centralization. To do otherwise would be tantamount to ignoring the vast, accumulated evidence base and would ultimately be a disservice to patients afflicted with this highly lethal disease.

Competing interests: The author reports no competing personal or financial interests related to this work.

\section{References}

1. Siemens DR, Visram K, Wei $X$, et al. Effect of centralization on complex surgical care: $A$ population-based case study of radical cystectomy. Can Urol Assoc J 2020;14:91-6. https://doi.org/10.5489/cuai.5998

2. Williams SB, Ray-Zack MD, Hudgins HK, et al. Impact of centralizing care for genitourinary malignancies to high-volume providers: A systematic review. Eur Urol Oncol 2019;2:265-73. https://doi.org/10.1016/j. evo.2018.10.006

3. Afshar M, Goodfellow H, Jackson-Spence F, et al. Centralization of radical cystectomies for bladder cancer in England, a decade on from the 'Improving Outcomes Guidance': The case for super centralization. BJU Int 2018;121:217-24. https://doi.org/10.1111/bju.13929

4. Finks JF, Osborne NH, Birkmeyer JD. Trends in hospital volume and operative mortality for high-risk surgery. N Engl J Med 2011;364:2128-37. https://doi.org/10.1056/NEJMsa1010705

5. National Institute for Clinical Excellence. Guidance on cancer services Improving outcomes in urological cancers. The manual (September 2002). Available at: https://www.nice.org.uk/guidance/csg2. Accessed Feb. 20, 2020

6. Arora S, Keeley J, Patel A, et al. Defining a "high-volume radical cystectomy hospital: Where do we draw the line? Eur Urol Focus 2019;pii:S2405-4569(19)30018-5. https://doi.org/10.1016/j. euf.2019.02.001

7. Gray WK, Day J, Briggs TWR, et al. Understanding volume-outcome relationships in nephrectomy and cystectomy for cancer: Evidence from the UK "Getting it Right First Time" program. BJU Int 2020;125:23443. https://doi.org/10.1111/biu. 14939

8. Sahni NR, Dalton M, Cutler DM, et al. Surgeon specialization and operative mortality in United States: Retrospective analysis. BMJ 2016;354:33571. https://doi.org/10.1136/bmi.i3571

9. Bhindi B, Yu J, Kuk C, et al. The importance of surgeon characteristics on impacting oncologic outcomes for patients undergoing radical cystectomy. J Urol 2014;192:714-9. https://doi.org/10.1016/i. juro.2014.02.093

10. Kassouf W, Aprikian A, Saad F, et al. Improving patient journey and quality of care: Summary from the second Bladder Cancer Canada-Canadian Urological Association-Canadian Urologic Oncology Group (BCC-CUA-CUOG) bladder cancer quality of care consensus meeting. Can Urol Assoc J 2018;12:E281-97. https://doi.org/10.5489/cuaj.5246

Correspondence: Dr. Girish S. Kulkarni, Department of Surgical Oncology, Princess Margaret Cancer Centre and the University Health Network, University of Toronto, Toronto, ON, Canada; Girish.Kulkarni@uhn.co 